\title{
Timing of surgery for pulmonary embolism: An evolving paradigm
}

\author{
Marc de Perrot, MD, MSc, FRCSC
}

\footnotetext{
From the Division of Thoracic Surgery, Toronto General Hospital, University Health Network, Toronto, Ontario, Canada.

Disclosures: Author has nothing to disclose with regard to commercial support.

Received for publication Sept 28, 2017; accepted for publication Oct 7, 2017; available ahead of print Nov 28 , 2017.

Address for reprints: Marc de Perrot, MD, MSc, FRCSC, Director, Toronto CTEPH Program, Division of Thoracic Surgery, Toronto General Hospital, 200 Elizabeth St, Ontario M5G 2C4, Canada (E-mail: marc. deperrot@uhn.ca).

J Thorac Cardiovasc Surg 2018;155:1091-2

$0022-5223 / \$ 36.00$

Copyright (C) 2017 Published by Elsevier Inc. on behalf of The American Association for Thoracic Surgery https://doi.org/10.1016/j.jtcvs.2017.10.011
}

The article in this issue of the Journal from Lee and coworkers $^{1}$ presents the outcome of acute pulmonary embolism (PE) from a statewide database in New York State between 1999 and 2013. Although the study has inherent limitations because of the use of a large, disparate database, Lee and coworkers ${ }^{1}$ noted several important points. The 30-day mortality was similar between patients treated with thrombolysis and those treated with surgical embolectomy. Thrombolysis was associated with a lower risk of major bleeding but with a higher risk of stroke. A cardiac surgery facility was available in a third of the centers where acute PE was treated, but its availability did not influence outcomes. After a median follow-up of longer than 4 years, the 5-year survival was $72.4 \%$ in the thrombolysis group and $76.1 \%$ in the surgical embolectomy group. Although the rate of recurrent PE was similar between the groups, with cumulative recurrent $\mathrm{PE}$ incidences of $18.8 \%$ after thrombolysis and $20 \%$ after surgical embolectomy, the rate of hospital admission for recurrent $\mathrm{PE}$ was significantly higher in the thrombolysis group $(7.9 \%)$ than in the surgical embolectomy group $(2.8 \%)$. Overall, the findings from this study are in line with those of some other recent studies that have suggested that surgical embolectomy is as safe as thrombolysis but carries less risk of stroke in the early period and potentially has a better long-term outcome because of a greater extend of clot removal. ${ }^{2}$

So where does surgical embolectomy currently fit into the treatment algorithm for acute PE?

When considering surgery for acute PE, it is important to differentiate patients with massive PE presenting in a state of hemodynamic instability (high-risk category) from those with submassive PE presenting with right ventricular dysfunction alone (intermediate-risk category). In the high-risk group, surgical embolectomy is a lifesaving procedure that should always be considered as a primary option, or as a secondary option after thrombolysis. In the absence of any randomized trials, surgical embolectomy is generally recommended after unsuccessful thrombolysis rapid response team.

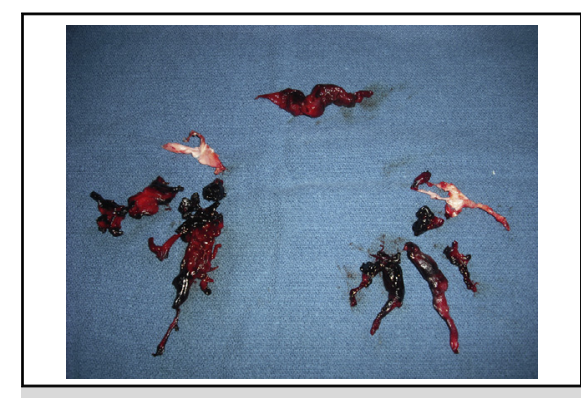

Submassive pulmonary embolism can include a component of chronic thromboembolic disease.

\section{Central Message}

Thrombolysis and surgical embolectomy are treatments of choice for acute pulmonary embolism with hemodynamic instability. The best option should be selected by a multidisciplinary rapid response team.

See Article page 1084.

or when thrombolysis is contraindicated. ${ }^{3}$ The decision between thrombolysis and surgery should be made on an individual basis, however, ideally by a multidisciplinary

In the intermediate-risk category, on the other hand, the balance between the roles of surgical embolectomy and thrombolysis is still controversial. In my own center, with a few exceptions such as the presence of a clot in transit (Figure 1), we treat intermediate-risk PE conservatively during the acute phase, with careful monitoring, and intervene only if hemodynamic instability ensues. This category of patients has an overall 30-day mortality of less than $5 \%$, and in the absence of hemodynamic instability, the risk associated with surgery may therefore be greater than the risk of conservative treatment. During the past few years, it has also become increasingly well documented that chronic thromboembolic disease can present acutely in some patients and mimic the clinical picture of a submassive PE. ${ }^{4}$ Because of the chronic component of the disease, intermediate-risk patients may have an adapted right ventricle, and despite an enlarged and dysfunctional right ventricle, these patients therefore are not hemodynamically compromised. Proceeding with a pulmonary embolectomy in that group of patients would potentially be an unnecessary surgery. This observation is supported by a large randomized trial demonstrating that thrombolysis in intermediate-risk patients does not improve survival or 


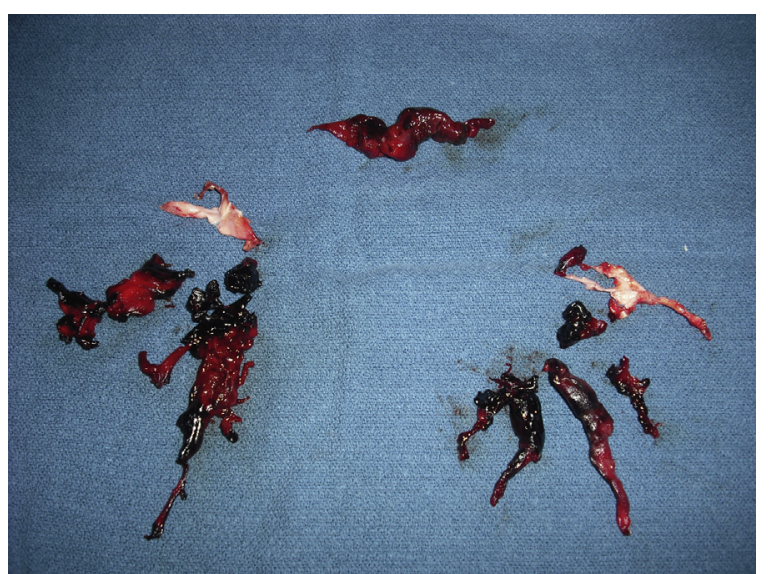

FIGURE 1. Submassive pulmonary embolism can contain a component of chronic thromboembolic disease. This specimen came from a patient who had a submassive pulmonary embolism that was treated surgically for a in transit.

decrease the rate of residual dyspnea or right ventricular dysfunction in the long term. ${ }^{5}$ It is therefore my opinion that surgery for submassive PE (intermediate-risk category) should be delayed if possible. This conservative treatment will provide an opportunity to determine the extent of the chronic component of the disease and to allow the right ventricle to recover as much as possible before any pulmonary thromboendarterectomy that may be required.

\section{References}

1. Lee T, Itagaki S, Chiang YP, Egorova NN, Adams DH, Chikwe J. Survival and recurrence after acute pulmonary embolism treated with pulmonary embolectomy or thrombolysis in New York State, 1999-2003. J Thorac Cardiovasc Surg. 2018; 155:1084-90.

2. Lehnert P, Møller CH, Mortensen J, Kjaergaard J, Olsen PS, Carlsen J. Surgical embolectomy compared to thrombolysis in acute pulmonary embolism: morbidity and mortality. Eur J Cardiothorac Surg. 2017;51:354-61.

3. Konstantinides SV, Torbicki A, Agnelli G, Danchin N, Fitzmaurice D, Galiè N, et al; Task Force for the Diagnosis and Management of Acute Pulmonary Embolism of the European Society of Cardiology (ESC). 2014 ESC guidelines on the diagnosis and management of acute pulmonary embolism. Eur Heart J. 2014;35:3033-69. 3069a-3069k. Erratum in: Eur Heart J. 2015;36:2666. Erratum in: Eur Heart J. 2015;36:2642.

4. Guérin L, Couturaud F, Parent F, Revel MP, Gillaizeau F, Planquette B, et al. Prevalence of chronic thromboembolic pulmonary hypertension after acute pulmonary embolism. Prevalence of CTEPH after pulmonary embolism. Thromb Haemost. 2014;112:598-605.

5. Konstantinides SV, Vicaut E, Danays T, Becattini C, Bertoletti L, BeyerWestendorf $\mathrm{J}$, et al. Impact of thrombolytic therapy on the long-term outcome of intermediate-risk pulmonary embolism. J Am Coll Cardiol. 2017; 69:1536-44. 